\title{
Definição e abordagem de currículo: exame de um curso de formação de professores para a educação não formal em ONGS
}

\author{
Definition of curriculum and approach: study of a training course for \\ teachers of non-formal education in NGOs
}

Resumo Este artigo apresenta pesquisa cujo objetivo foi analisar a definição e abordagem de currículo norteadores da formação de professores para o trabalho na educação não formal em organizações não governamentais (Ongs). Optou-se pela perspectiva qualitativa de pesquisa e estudo de caso do $\mathrm{C}$ urso Formação de Professores para Ongs, desenvolvido por Ong de São Paulo-SP. Os instrumentos de pesquisa foram: análise dos documentos do curso, entrevistas semidiretivas com formadores e coordenador e revisão da literatura. Nesse curso, define-se currículo como caminho a ser percorrido por alunos e formadores e como organizador das temáticas estudadas. Adota-se abordagem nomeada Currículo Integrado, em que o ensino ocorre pelo estudo de situações-problema e projetos integradores das aprendizagens. Ao final, sugere-se aperfeiçoamento do curso e seguem informações que, espera-se, apoiem a produção ulterior de pesquisas comparativas.

PALAVRAS-CHAVE: Currículo, Formação de professores, Educação não formal.

\begin{abstract}
This article presents a research aimed to analyze the approach and the definition of guiding curriculum of teacher training for work in the non-formal education in non-governmental organizations (NGOs). We opted for a qualitative approach and case study of Teacher Training Course for NGOs, developed by Ong São Paulo-SP. The research instruments were: analysis of documents of the course, interviews with trainers and coordinator and literature review. In this course, curriculum is defined as a path to be followed by students and instructors and the coordinator of the subjects studied. We adopted the so-called Integrated Curriculum, in which teaching occurs by the study of problem situations and integrators of learning projects. At the end, we suggest improving the course and following that information, it is hoped, one will support the production of further comparative research.
\end{abstract}

KEYWORDS: Curriculum, Teacher training, Non-formal education. 


\section{Introdução}

Este artigo tem como objetivo apresentar pesquisa acadêmico-científica dedicada à análise e compreensão da definição teórica e da abordagem ou modelo de currículo que organiza e norteia o processo formativo de professores para o trabalho na educação não formal, desenvolvido em organizações não governamentais (Ongs). O exame da temática foi feito por meio da recolha, sistematização e estudo de dados relativos a um curso, nomeado Formação de Professores para Ongs, que foi organizado e realizado por uma Ong sediada em São Paulo-SP. Este curso teve como participantes profissionais, voluntários e ativistas que trabalhavam ou pretendiam atuar em Ongs, os quais foram denominados "alunos" nesta pesquisa.

Cumpre destacar que o curso examinado, não somente dedica-se a capacitar docentes para a educação não formal realizada por Ongs, como também esta inserido, ele próprio, nesta modalidade educacional, em função de ter sido desenvolvido por instituição que não pertence ao sistema brasileiro de escolarização formal. A educação não formal é definida como aquela que, analogamente à educação formal ou escolar, se caracteriza pela intencionalidade de ensinar, por parte dos agentes educacionais (professores, monitores, educadores, tutores, etc.) e de aprender, pelos alunos ou participantes do processo de ensino e aprendizagem. De acordo com Perez (2009), a educação não formal é estruturada e promovida por indivíduos, grupos ou organizações que compreendem a necessidade de realizar, de modo estruturado e intencional, o ensino de determinados conhecimentos ou saberes e práticas, voltado para pessoas e grupos que, deliberadamente, buscam construir aprendizagens que lhes sejam significativas. $\mathrm{O}$ que marca esta modalidade de educação e que a distingue da educação formal é exatamente o fato de suas atividades ocorrerem fora do sistema de escolarização. Outra diferença importante entre as duas modalidades educacionais é que há exigência legal de formação acadêmica específica para o exercício da docência na educação formal, o que não se observa na educação não formal. Em função disso, temos como docentes da educação não formal profissionais como: sociólogos, psicólogos, nutricionistas, arquitetos, jornalistas, economistas, matemáticos, assistentes sociais, pedagogos, enfermeiros, dentistas, entre outros. Esta multiplicidade de profissionais que assumem a docência como ofício no campo da educação não formal, demanda atenção ao processo formativo para o trabalho educacional, de modo a evitar ações de ensino e aprendizagem que sejam marcadas pela ausência de profissionalismo e pelo desconhecimento das teorias e práticas educacionais.

A hipótese levantada, nesta investigação, foi que o curso analisado teria uma abordagem e prática curricular flexível e capaz de atender de modo dinâmico as demandas de aprendizagem dos alunos. Isto considerando, conforme mencionado acima, que se trata de processo formativo do campo da educação não formal, que tem como uma de suas características centrais a possibilidade de oferecer atividades de ensino a partir das demandas de aprendizagem apresentadas por grupos de pessoas e indivíduos.

Antes do relato da pesquisa, é preciso informar que, por solicitação dos participantes, foi alterado o nome da Ong, aqui denominada Ong Formadora, e as informações que pudessem identificar os formadores e coordenador do curso, que participaram voluntariamente do estudo, sem qualquer prejuízo para o entendimento dos dados e reflexões sobre a temática examinada. 
O interesse pela identificação e análise da definição e modelo de currículo orientadoras da capacitação de professores para Ongs justifica-se pela ampliação da relevância e presença na sociedade destas organizações. De acordo com pesquisa divulgada em 2012, pelo Instituto Brasileiro de Geografia e Estatística (IBGE), havia no país, em 2010, mais de duzentas e noventa mil Ongs, que empregavam cerca de dois milhões e cem mil trabalhadores. Além das pessoas que possuem vinculo empregatício formal com Ongs, estima-se que $16 \%$ da população economicamente ativa do Brasil realiza atividades voluntariamente, todos os anos, nestas organizações. Ainda, é preciso notar que a atuação das Ongs e a atividade de seus trabalhadores estão relacionadas a setores tão distintos e estratégicos quanto educação, cultura, saúde, assistência social, comunicação, pesquisa, lazer, religião, entre outros. Parece evidente, portanto, que se não houver um adequado conhecimento a respeito dos referenciais teóricos e práticos adotados por estas organizações, para a capacitação dos seus trabalhadores, estarão ausentes as condições básicas para uma análise profunda, crítica e abrangente acerca do alcance, qualidade, relevância e limitações do trabalho desenvolvido naquelas organizações.

A escolha do tema de pesquisa se justifica, também, devido à escassez de pesquisas sobre a educação não formal executada por Ongs e a formação de seus professores, conforme aponta levantamento que realizamos considerando os dados tornados disponíveis pela Coordenação de Aperfeiçoamento de Pessoal de Nível Superior (CAPES), que possui um banco digital com mais de 125 mil pesquisas que resultaram na produção de teses e dissertações no Brasil. Neste banco de teses, entre 1988 e dezembro de 2012, foram localizados setenta e sete estudos sobre Ongs. Esses estudos foram realizados em áreas diversas, tais como contabilidade, psicologia social, serviço social, artes, sociologia e, predominantemente, nos campos da administração e da educação. Especificamente entre as teses e dissertações da área de educação, foram abordados temas como: as vinculações entre o trabalho das Ongs e a desresponsabilização do Estado em relação à educação (COUTINHO, 2005); e a gestão de Ongs que atuam na educação infantil (COSTA, 2004). Sobre o tema formação de professores para educação não formal realizada por Ongs, foram encontrados três trabalhos, sendo duas dissertações de mestrado realizadas, respectivamente, por Santana (1991) e Perez (2004), e uma tese de doutorado (PEREZ, 2009). Esses dados pareceram reafirmar a necessidade de aprofundar os esforços em torno da produção de saberes sobre a temática em tela.

A escolha do curso Formação de Professores para Ongs, como espaço para a recolha dos dados desta pesquisa, justifica-se por ser o único oferecido na cidade de São Paulo, nos últimos dois anos (2011-2012). Este curso formou três turmas de professores para o trabalho em Ongs, sendo a primeira no ano de 2011 e a última no segundo semestre de 2012. O curso foi escolhido, também, por ter sido elaborado e realizado por uma Ong que, hipoteticamente, tem interesse e potencial para favorecer um processo formativo sintonizado com as principais práticas e teorias que circulam contemporaneamente no país sobre a educação não formal.

É relevante destacar que a análise do curso foi feita a partir da circunscrição de categorias empíricas de referências e dados. As categorias empíricas, conforme Franco (2008), são aquelas que emergem das informações obtidas diretamente no campo de pesquisa. Somente após a obtenção destes dados, é que se buscou na literatura acadêmica especializada identificar os referenciais teóricos que se articulavam, apro- 
ximavam ou apresentavam oposição às informações empíricas. Portanto, evitou-se a delimitação de categorias teóricas a priori, que antecipassem os dados provenientes do campo de pesquisa. Neste artigo buscou-se registrar este movimento dialético entre as informações empiricamente obtidas e, na sequencia, as teorias a elas relacionadas.

Este texto está organizado em três subseções, além desta introdução, no qual abordamos, sucessivamente: a) a perspectiva metodológica e o contexto de recotha dos dados; b) a definição e abordagens de currículo presentes no curso analisado; c) considerações finais.

\section{Metodologia de pesquisa e contexto de recolha dos dados}

No tocante à metodologia, optou-se pela realização de uma pesquisa qualitativa, em que os dados coletados são mais descritivos e procuram captar o discurso e a percepção das pessoas sobre um problema ou situação. Corroborou essa opção a indicação de Antonio Chizzotti, segundo o qual a adoção da abordagem qualitativa de pesquisa deve ocorrer nos casos em que o pesquisador considerar que "o mundo deriva da compreensão que as pessoas constroem no contato com a realidade nas diferentes interações humanas e sociais" (CHIZZOTTI, 2010, p. 69).

A partir dos aspectos acima mencionados e do estudo dos diferentes tipos de pesquisa qualitativa, foi que se decidiu pela realização de um estudo de caso. A pesquisadora Marli André sinaliza que o estudo de caso caracteriza-se por ser um "[...] estudo em profundidade de um fenômeno, com ênfase na sua singularidade [...]" (ANDRÉ, 2003, p. 19). Nesta pesquisa, foi realizado o que Stake (1995 apud ANDRÉ, 2003) denominou estudo de caso instrumental, em que o interesse do pesquisador é o exame de um tema amplo, que a análise de um caso em particular ajudará a elucidar. As indicações de Stake vieram ao encontro do que se pretendia nesta pesquisa, que era conhecer a definição e abordagem de currículo de um processo formativo de docentes para a educação não formal desenvolvida nas Ongs.

Finalmente, foram selecionados os instrumentos de recolha dos dados, que foram: revisão crítica da literatura pertinente ao tema; entrevistas individuais e coletivas de tipo semidiretivas com formadores e coordenador da formação; análise de documentos orientadores do curso examinado. A entrevista foi adotada porque representa, de acordo com André (1986), um instrumento básico da pesquisa qualitativa, e permite, ao entrevistado, discorrer sobre o tema sugerido, a partir de suas vivências e percepções. Foi utilizada a entrevista de tipo semidiretiva, que "é aquela que parte de certos questionamentos básicos, apoiados em teorias e hipóteses que interessam à pesquisa, e que, em seguida, oferecem amplo campo de interrogativas [...]" (TRIVIÑNS, 1995, p. 146).

Participaram da pesquisa três sujeitos, que contribuíram voluntariamente. Foram realizadas entrevistas individuais e coletivas com dois formadores do curso (doravante, formador "A" e formador "B"), e com o profissional responsável pela sua coordenação, que também é formador do curso (aqui nomeado coordenador). Os documentos examinados foram: o Plano Pedagógico e as ementas dos diferentes módulos do curso; os manuais ou apostilas do formador, com a descrição das atividades que devem ser realizadas nas aulas; as ementas das disciplinas que compõem cada módulo do curso e os planos de trabalho elaborados pelos próprios formadores. 
O curso estudado possuía carga horária total de 192 horas, realizadas aos sábados em período integral, distribuídas em quatro módulos, que se subdividiam disciplinas. $\mathrm{O}$ final do curso foi dedicado à elaboração, pelos participantes, de um projeto educacional implementado em uma Ong. Esse projeto foi construído e desenvolvido em subgrupos de alunos, sob orientação de um formador. O período de elaboração deste projeto e o princípio da sua implantação faziam parte do currículo, mas a totalidade da implementação do projeto e a avaliação dos resultados alcançados eram consideradas atividades separadas do curso e, portanto, não certificadas. A duração das atividades formativas foi de aproximadamente seis meses. Os quatro módulos do curso eram: a) Módulo 1 - Apresentação e proposta de debates em torno da temática "contextos social, político e econômico e a educação em Ongs", com 52 horas de duração; b) Módulo 2 - "Ferramentas de trabalho do professor na educação na formal", dedicado à instrumentalização teórica e técnica para o aluno assumir o ofício docente, com 40 horas de duração; c) Módulos 3 - "Projeto prático de educação", que ofereceu os subsídios teóricos para a elaboração de um projeto socioeducacional a ser desenvolvido concretamente pelo participante do curso em uma Ong. O módulo teve 64 horas de duração; d) Módulo 4 - Início da implantação de Projeto Prático de Educação em Ong, com 36 horas de duração.

O processo de recolha dos dados foi orientado para garantir que fossem reconhecidos o conceito e a abordagem de currículo adotadas no curso. Segue o relato das análises de pesquisa que, conforme mencionado, partirá das informações empíricas para a articulação com as referências acadêmico-científicas disponíveis na literatura pertinente ao tema.

\section{A definição e as abordagens de currículo presentes no curso analisado}

Inicialmente, buscou-se identificar a definição de currículo adotada pelos formadores e coordenador do curso. A delimitação de currículo foi descrita com assertividade, por um dos formadores do curso, que, em seu depoimento, afirmou: "O currículo para nós é o caminho que será percorrido. Nós somos parceiras dos alunos nesse caminho" (Formador "A", Entrevista semidiretiva, 2012). O coordenador do curso reforça esta definição de currículo, enquanto caminho a ser percorrido, ao indicar que:

[...] não poderia ser de outra forma. $\mathrm{O}$ currículo é como se fosse a estrada que vamos trilhar. E vamos juntos com nossas alunas. A gente sabe que as coisas poderão sofrer alterações. Mas há um caminho ideal imaginado. O objetivo do curso, as competências que as alunas desenvolverão serão as mesmas que foram traçadas. Dependendo da turma, podemos pegar atalhos, desviar um pouco do trajeto inicial, que é o currículo escrito. (Coordenador do curso Formação de Professores para Ongs, Entrevista semidiretiva, 2012)

A definição explicitada tem relação com as origens da palavra currículo, conforme registra a literatura educacional especializada. Entre os teóricos que abordam a genealogia do termo curriculum, pode-se mencionar David Hamilton (1992), Gimeno Sacristán (1999) e Ivor Goodson (2002). Eles concordam que o termo curriculum teve como origem uma palavra latina, cujos significados possíveis seriam corrida ou pista de corrida (HAMILTON, 1992), carro de corrida (GOODSON, 2002), ou percurso de corrida (SACRISTÁN, 2000). Há uma pequena divergência acerca da grafia 
correta do vocábulo latino que originou a palavra curriculum: Segundo Goodson, o termo latino seria Scurrere, enquanto Sacristán indica como grafia adequada Currere. De qualquer modo, o conjunto de significados apontados pelos autores remete à noção de percurso ou caminho a ser percorrido. Exatamente a mesma definição do formador e do coordenador do curso. Além desta delimitação de currículo, há outra que surgiu quando foram analisados os registros do manual do formador do curso, em que havia indicação de que o currículo poderia ser definido mais como "o elemento organizador do conjunto de temas, teorias e práticas que devem ser priorizados no processo formativo dos professores, do que como o instrumento de controle do comportamento e do pensamento dos formadores e alunos" (ONG FORMADORA, 2011b). Assim, é possível sinalizar que a definição de currículo adotada no curso, que articula as indicações dos formadores nas entrevistas e os registros contidos nos documentos prescritivos do curso, está sintonizada com a percepção de César Coll, segundo o qual o currículo deve ser compreendido como:

[...] o projeto que preside as atividades educativas escolares, define suas intenções e proporciona guias de ação adequadas e úteis para os professores, que são diretamente responsáveis pela sua execução. Para isso o currículo proporciona informações concretas sobre o que ensinar, quando ensinar e o que, como e quando avaliar. (COLL, 1999, p. 45)

Especificamente sobre a estruturação e organização curricular do curso, nota-se que houve uma tentativa de inovar no encadeamento e ordenamento sequencial dos conteúdos e temáticas abordadas no processo educativo:

[...] Desde o princípio (momento da criação do curso), era claro que os temas do curso não iriam resultar em disciplinas tradicionais, que ficam separadas umas das outras.. Elas (as disciplinas) são itens que organizam a vinda dos formadores para ministrar as aulas e fazem com que os alunos saibam o tema geral do dia. Desde o começo tentamos criar um curso que tivesse as disciplinas como um suporte da organização do curso e não como o centro das aprendizagens, você entende? Não queríamos ter um curso multidisciplinar. Não combina com as Ongs, que atuam com problemas e com pessoas de uma forma integral. (Coordenador do curso Formação de Professores para Ongs, Entrevista semidiretiva, 2012)

O depoimento conduz a uma primeira constatação: a forma de as disciplinas do curso se relacionarem é um aspecto relevante para a compreensão da abordagem curricular que o orienta. Por esta razão, é necessário delimitar, com exatidão, os conceitos de multidisciplinaridade, interdisciplinaridade e transdisciplinaridade. É preciso ter presente que os três conceitos partem do reconhecimento da existência das disciplinas, compreendidas como formas de organizar os conteúdos educacionais. Pode-se definir disciplina como a unidade básica que reúne e organiza os conteúdos e saberes de um campo ou objeto particular de estudos. A própria existência das disciplinas pressupõe o parcelamento do saber. Em um curso organizado por disciplinas, é possível identificar o grau de integração e relação entre elas. É o nível destas relações que determina se um curso é multidisciplinar, interdisciplinar ou transdisciplinar. O pesquisador Antoni Zabala indica que: 
A multidisciplinaridade é a organização de conteúdos mais tradicional. Os conteúdos escolares são apresentados por matérias independentes umas das outras [...]. A interdisciplinaridade é a interação entre duas ou mais disciplinas, que pode ir desde a simples comunicação de ideias até a integração recíproca de conceitos fundamentais [...]. A transdisciplinaridade é o grau máximo de relações entre as disciplinas, daí que supõe uma integração global dentro de um sistema [...] atualmente, constitui mais um desejo do que uma realidade. (ZABALA, 1998, p. 143-4)

Considerando o exposto acima e os dados coletados nas entrevistas, pode-se afirmar que, no curso estudado, a interação entre as disciplinas está predominantemente no nível da interdisciplinaridade, podendo assemelhar-se à transdisciplinaridade, em algumas poucas situações, particularmente, no final do curso, nas atividades relacionadas ao Projeto Prático de Educação, que é quando os formadores e os alunos realizam um esforço para integrar os saberes construídos ao longo da formação. Há, aparentemente, um empenho dos formadores para alcançar a transdisciplinaridade, mas eles reconhecem a dificuldade para uma efetiva aproximação desse grau de relação entre as disciplinas.

[...] buscamos a integração plena entre as disciplinas, mas isso implica em manter a equipe de formadores em contato constante, em espaços institucionalmente reconhecidos, em minha opinião. Para isso, seria preciso ampliar os recursos investidos no curso, e não temos condições de cobrar mais dos alunos e nem de aumentar a carga horária de trabalho dos formadores. (Coordenador do curso Formação de Professores para Ongs, Entrevista semidiretiva, 2012)

O elemento determinante para que o curso apresente maior nível de relação e interação entre as disciplinas parece ser o Projeto Prático de Educação (doravante, Projeto), conforme indicado no Plano Pedagógico. O Projeto Prático auxilia os formadores e alunos na realização da gestão e da integração das aprendizagens. Por meio do Projeto, os alunos dedicam-se ao estudo de uma situação-problema, que é a criação de um programa educacional para uma Ong real. A elaboração do Projeto faz com que as disciplinas ministradas, dirijam seu foco para os problemas concretos que envolvem a realização desta atividade. O processo de elaboração e desenvolvimento do Projeto parecem seguir o que Fernando Hernandéz (1998) denominou globalização dos conteúdos, que nada mais é que a busca por formadores e alunos, do estabelecimento de nexos significativos entre os conteúdos das diferentes disciplinas de modo a apoiar a solução de situações complexas que se apresentam em um projeto que deve ser realizado.

Levando em conta que o curso adota, com ênfase, o trabalho por projetos educacionais e que há efetiva tentativa de organização dos conteúdos de forma interdisciplinar, tendendo para a transdisciplinaridade, muito provavelmente a abordagem curricular que está subjacente a toda a estruturação do curso é aquela chamada Currículo Integrado, que tem como base as propostas educacionais de John Dewey, Willian Kilpatrick, Ovide Decroly e os métodos globalizadores de educação. O Currículo Integrado caracteriza-se por ser:

[...] organizado não só em torno de disciplinas, como costuma ser feito, mas de núcleos que ultrapassam os limites das disciplinas, centrados em temas, problemas, tópicos, instituições, períodos históri- 
cos, espaços geográficos, grupos humanos, ideias, etc. [...] os alunos seriam obrigados a manejar referenciais teóricos, conceitos, procedimentos, habilidades de diferentes disciplinas, para compreender ou solucionar as questões e problemas propostos. (SANTOMÉ, 1998, p. 25)

Aparentemente, em conformidade com Santomé (1998), é este manejo dos referenciais teóricos, conceitos e procedimentos de disciplinas diversas, que marca o curso analisado. Não ocorre a negação ou a eliminação das disciplinas, mas elas parecem estar, em especial, nos módulos 3 e 4, à serviço da análise e da solução de problemas impostos pela realidade das Ongs, que se manifestam no planejamento e implantação dos Projetos Práticos de Educação dos alunos. O currículo do curso mostra-se capaz de favorecer a aproximação entre os conteúdos teóricos e a realidade de trabalho que os profissionais em formação encontrarão nas Ongs. Neste sentido, a estrutura e o texto curricular do curso, presente no seu Projeto Pedagógico, parecem atender a um dos princípios fundamentais que, segundo Sacristán, tornam um currículo mais educativo, a saber: "estabelecer as conexões interdisciplinares possíveis entre as áreas e disciplinas: para compreender melhor a realidade, [...] aplicar o conhecimento à resolução de problemas, [...] descobrir interdependências epistêmicas e metodológicas" (SACRISTÁN, 2007, p. 126).

O trabalho educacional organizado a partir da perspectiva do Currículo Integrado seria uma forma de favorecer a compreensão de situações complexas, pelos alunos. É, neste contexto, que o trabalho por projetos é inserido no curso estudado como um elemento que visa garantir a integração e entendimento dos saberes pelos alunos. Aparentemente, o projeto é que permite que o curso seja percebido como interdisciplinar e que oferece as condições necessárias para que o Currículo Integrado possa ser implementado com maior eficiência. Isso ocorre porque as Ongs, onde cada subgrupo de alunos realiza o seu Projeto Prático de Educação, não se caracterizam como espaços apenas visitados pelos alunos. Eles devem realizar intervenções concretas, e lidar com todos os aspectos constitutivos da realidade das Ongs e da elaboração e desenvolvimento efetivo de um programa educacional.

\section{Considerações finais}

A guisa de conclusão, cumpre lembrar que este trabalho de pesquisa voltou-se para a identificação e análise da definição e abordagem ou modelo de currículo que norteiam e estruturam o processo formativo dos professores para a educação não formal realizada em Ongs. No caso do curso examinado, Formação de Professores para Ongs, o currículo é definido como "o caminho a ser percorrido pelos alunos, em parceria com os formadores e demais atores envolvidos no processo formativo". Trata-se de perspectiva que tem relação com a própria origem da noção de currículo, conforme os registros disponíveis na literatura educacional. A essa definição, mais ampla e menos específica de currículo, pôde-se notar que está vinculada uma definição complementar e mais precisa, apontando que a estrutura curricular do curso seria o elemento organizador do conjunto de temas, teorias e práticas que devem ser priorizados, no processo formativo dos professores.

A abordagem curricular adotada é a denominada Currículo Integrado, no qual o ensino ocorre pelo estudo de situações complexas e projetos, que favorecem a 
integração e mobilização de conceitos, habilidades e referenciais teóricos diversos com vistas à compreensão do tema estudado. Vale destacar que a estrutura curricular do curso poderia ser interpretada como vinculada a abordagem nomeada Currículo em Rede de Conhecimentos, que consiste na organização dos saberes teóricos, práticos, sociais, etc., de forma não linear e em estrutura de espiral com complexidade crescente de conteúdos educacionais (MACEDO; LOPES, 2005). A essência do Currículo em Rede está na valorização dos conhecimentos construídos nas vivências cotidianas reais dos alunos. Nesta abordagem, não se nega a importância da teoria, mas o saber acadêmico-científico deixa de ser o eixo central da construção do currículo, que volta-se para o saber produzido cotidianamente pelas pessoas. Nesse sentido estrito, há semelhança entre a abordagem curricular em rede e o currículo integrado. A diferença entre estes tipos de currículo reside no fato de o Currículo Integrado manter no centro do processo educativo os saberes acadêmico-científicos. $\mathrm{O}$ curso analisado apresenta esta ênfase nos saberes acadêmicos e científicos, apontada em seu Plano Pedagógico (ONG Formadora, 2011a, p. 03), segundo o qual "[...] o centro do processo de aprendizagem será os saberes científicos, que deverão ser constantemente submetidos à análise crítica por professores e alunos".

Outra possibilidade analítica da estrutura do curso estudado seria considerá-lo inserido na perspectiva do hibridismo curricular que, conforme Macedo e Lopes (2005), se caracteriza pela quebra e mistura de múltiplas influências teóricas na construção e aplicação de um currículo. A despeito disso, optamos, nesta pesquisa, por indicar que o modelo curricular predominante no curso examinado era o Currículo Integrado, conforme explicitado na seção anterior. Isto porque consideramos que o hibridismo curricular parece ser mais uma forma de análise histórica das práticas curriculares brasileiras que uma abordagem de currículo com corpus teórico construído e consolidado na literatura acadêmica educacional.

Cumpre acrescentar que o "Projeto Prático de Educação" realizado no curso, possui marcas ou características singulares que obedecem alguns dos aspectos caracterizadores de um projeto de trabalho educacional, conforme descrito por Hernandéz (1998). O autor apresenta nove características que devem estar presentes em um projeto, com vistas à construção do conhecimento em um processo educativo. $\mathrm{O}$ curso estudado contempla, segundo a análise realizada, algumas das características descritas pelo pesquisador espanhol. Em síntese, em conformidade com Hernandéz (1998), as características presentes no curso são: a) predomínio de uma atitude de cooperação entre os envolvidos no projeto; b) respeito ao percurso singular de cada projeto desenvolvido pelos alunos do curso; c) a aprendizagem ligada ao fazer, na medida em que o projeto feito no curso é concretizado em uma Ong real; d) percurso por um tema que permite aos alunos a análise, a interpretação e a crítica de toda a situação-problema que está sendo estudada e que se procura propor soluções.

Entretanto, curiosamente, os formadores consideram que a completa implantação do Projeto Prático de Educação, realizado pelos alunos, é uma atividade apartada dos demais componentes curriculares do curso. O modo como o Projeto é realizado e a relevância que o trabalho prático em uma ONG assume, no processo formativo dos alunos, ensejam reflexões no sentido de considerar que a integralidade das aprendizagens construídas no trabalho de campo, deveria ser percebida pela equipe de formadores como parte do currículo do curso. É preciso que esse seja um aspecto previsto nos documentos do curso e nos discursos dos seus protagonistas. Sugerimos que 
seja adotada no curso, de forma complementar à perspectiva de Currículo Integrado, a noção de Currículo Ampliado, que diz respeito à inclusão de temas provenientes de campos do saber alternativos e não trabalhados em sala de aula, mas a ela incorporados a partir da demanda e das necessidades de aprendizagem dos alunos.

Dito de outra forma, o curso analisado se beneficiaria se mantivesse a noção de Currículo Integrado e incorporasse os saberes construídos pelos alunos na prática de implantação do Projeto. Assim, a estrutura do curso seria marcada também pela noção e práticas próprias do Currículo Ampliado, compreendido como o conjunto de teorias e saberes, práticas, comportamentos e valores, fundamentais para a formação e a educação de indivíduos e grupos, com os quais os alunos entram em contato em espaços múltiplos, externos à sala de aula e que não faziam parte do planejamento de conteúdos que ensinados pelo(s) formador(es), mas que são incorporados ao processo formativo, na medida em que emergem, em especial, a partir do contato dos alunos com a realidade concreta.

É importante ressaltar que trazer para dentro de um curso os saberes externos à sala de aula não implica na relativização ou a desvalorização dos saberes acadêmico-científicos. Considera-se, sim, que a noção de currículo deve contemplar às novas e abrangentes possibilidades de acesso ao conhecimento que demandam que o formador e os processos de ensino sejam cada vez menos instrucionais e cada vez mais norteadores do processo de aprendizagem dos alunos, capacitando-os para a coleta e análise crítica de informações e saberes socialmente produzidos.

Por fim, não se pode negar que o curso analisado apresenta um currículo flexível e voltado para a articulação interdisciplinar de saberes. Neste sentido, tratase de experiência importante e que deve ser compartilhada e registrada, tanto para a produção de cursos análogos e que se mostrem capazes de aperfeiçoar o modelo curricular adotado, quanto para auxiliar a produção de estudos acadêmicos comparativos ulteriores.

\section{Referências}

ANDRÉ, M. E. D.; LÜDKE, M. Pesquisa em educação: abordagens qualitativas. São Paulo: E.P.U., 1986. - (Temas Básicos de Educação e Ensino).

ANDRÉ, M. E. D. Etnografia da prática escolar. 9. ed. Campinas: Papirus, 2003. - (Série Prática Pedagógica).

CHIZZOTTI, A. Pesquisa em ciências humanas e sociais. 11. ed., São Paulo: Cortez, 2010.

COLL, C. Psicologia e currículo: uma aproximação psicopedagógica à elaboração do currículo escolar. Tradução de Claúdia Schilling, São Paulo: Editora Ática, 1999.

COSTA, J. R. F. da. A sociedade civil, utilitarismo e humanismo. 2004. Dissertação (Mestrado em Sociologia) Universidade Federal de Pernambuco. 2004.

COUTINHO, A. F. As organizações não-governamentais e a educação oferecida aos pobres: do consenso da oferta à ação privatizante. 2005. Tese (Doutorado em Educação). Universidade Federal do Rio Grande do Norte. 2005.

FRANCO, E. K. Currículo por projetos: inovação do ensinar e aprender na educação superior. 2008. Dissertação (Mestrado em Educação: Currículo) - Pontifícia Universidade Católica/ PUC-SP, São Paulo, 2008. 
GOODSON, I. F. Currículo: teoria e história. Trad. Attilio Brunetta. Petrópolis: Vozes, 2002.

HAMILTON, D. Sobre as origens dos termos classe e curriculum. Teoria \& Educação, n. 6, p. 33-51,1992.

HERNÁNDEZ, F. Transgressão e mudança na educação: os projetos de trabalho. Tradução de Jussara Haubert Rodrigues, Porto Alegre: ArtMed, 1998.

INSTITUTO BRASILEIRO DE GEOGRAFIA E ESTATÍSTICAS (IBGE). As fundações privadas e associações sem fins lucrativos no Brasil - 2010. Rio de Janeiro, 2012. Disponível em: <http://www.ibge.gov.br/home/estatistica/economia/fasfil/2010/default.shtm>. Acesso em: 10 mar. 2013.

MACEDO, E.; LOPES, A. C. (Orgs.). Currículo: debates contemporâneos. 2. ed., São Paulo: Cortez, 2005. - (Série cultura, memória e currículo, v. 2).

ONG FORMADORA. Proposta Estratégica da Ong FORMADORA. São Paulo, 2005. Documento de circulação interna.

Plano pedagógico do curso formação de professores para Ongs. São Paulo, 2011a. Documento de circulação interna.

. Manual do formador do curso formação de professores para Ongs. São Paulo, 2011b. Documento de circulação interna.

PEREZ, D. Formação de educadores para o terceiro setor. 2004. Dissertação (Mestrado em Educação, Arte e História da Cultura) - Universidade Presbiteriana Mackenzie, São Paulo, 2004.

. Formação de professores para organizações não-governamentais/ONGs. 2009. Tese (Doutorado em Educação: Currículo) - Pontíficia Universidade Católica de São Paulo/PUC -SP, São Paulo, 2009.

SACRISTÁN, J. G.; PÉREZ GOMÉZ, A. I. Comprender e transformar o ensino. Trad. Ernani da Fonseca Rosa. 4a ed. Porto Alegre: ArtMed, 1998.

Currículo: uma reflexão sobre a prática. 3. Ed. Tradução de Ernani F. Rosa. Porto Alegre: ArtMed, 2000.

A educação que ainda é possível: ensaios sobre uma cultura para a educação. Tradução de Valério Campos, Porto Alegre: ArtMed, 2007.

SANTANA, M. de M. Subsídios para uma teoria da prática pedagógica das ONG's: um estudo de caso - ETAPAS. 1991. Dissertação (Mestrado em Educação). Universidade Federal de Pernambuco, Pernambuco, 1991.

SANTOMÉ, J. T. Globalização e interdisciplinaridade: O currículo integrado. Tradução de Claudia Schilling, Porto Alegre: Artes Médicas Sul, 1998.

TRIVIÑOS, A. N. S. Introdução a pesquisa em ciências sociais: a pesquisa qualitativa em educação. São Paulo: Atlas, 1986.

ZABALA, A. A prática educativa: como ensinar. Tradução de Ernani F. da Rosa, Porto Alegre: ArtMed, 1998. 
Deivis Perez

* Professor Doutor da Universidade Estadual Paulista Júlio de Mesquita Filho, Assis, São Paulo - Brasil.

\section{Correspondência}

Deivis Perez - Universidade Estadual Paulista Júlio de Mesquita Filho, Faculdade de Ciências e Letras de Assis. Avenida Dom Antônio, Parque Universitário, CEP: 19806900, Assis, São Paulo - Brasil.

E-mail: prof.deivisperez@hotmail.com

Recebido em 29 de março de 2013

Aprovado em 01 de agosto de 2013 